\title{
MICROSURGICAL MANAGEMENT IN ANTERIOR COMMUNICATING ARTERY ANEURYSMS: AN ANATOMICAL INVESTIGATION
}

\author{
Ali Karadag ${ }^{1}$ \\ ${ }^{1}$ Department of Neurosurgery, Health Science University, Tepecik Research and Training Hospital, Izmir, Turkey \\ Address for Correspondence: Ali Karadag. E-mail: egealikaradag@gmail.com \\ Received: 05.01.2021; Accepted: 24.02.2021; Available Online Date: 04.03.2021 \\ CCopyright 2021 by Dokuz Eylül University, Institute of Health Sciences - Available online at https://dergipark.org.tr/en/pub/jbachs
}

Cite this article as: Karadag A. Microsurgical Management In Anterior Communicating Artery Aneurysms: An Anatomical Investigation. J Basic Clin Health Sci 2021; 1: 70-77.

\begin{abstract}
Purpose: The purpose of this study is to compare the pterional approach and the anterior interhemispheric approach for enabling a better surgical maneuverability. We describe the ideal the anatomic limitations of this surgery for anterior communicating artery aneurysms.

Methods: Four formalin-fixed and silicone injected human heads were used for each approach. Möller 201000 microscope (Wedel, Germany) was used for dissection and all the photographs were obtained at a similar angle to the surgical microscope, with Canon EOS Rebel T5 Digital SLR Digital Camera with an EF $100 \mathrm{~mm}$ f/2.8L Macro IS USM Lens and a Canon MR-14EX II Macro Ring Lite Flash (Canon Inc., Ohta-ku, Tokyo, Japan). Our dissection includes anterior interhemispheric and pterional approach with gyrus rectus resection and posterolateral orbitotomy.

Results: Pterional approach was performed followed by the gyrus rectus resection and posterolateral orbitotomy. This area can be exposed by the $1 \times 1 \mathrm{~cm}$ resection of the gyrus rectus. Subpial resection from posterior part of gyrus rectus is required. Posterolateral orbitotomy was performed and the orbital roof was removed. The anterior interhemispheric approach allows better visualization of the anterior and inferior surface of anterior communicating artery, A1-A2 junction and the optic nerve.

Conclusions: We believe that the pterional approach combined with gyrus rectus resection and posterolateral orbitotomy is more suitable for anterior, posterior and inferior type anterior communicating artery aneurysms. Also, anterior interhemispheric approach can be considered as safer route for superior and high positioned type.
\end{abstract}

Key words: Pterional, interhemispheric, orbitotomy, gyrus rectus, anterior communicating artery

\section{INTRODUCTION}

Anterior communicating artery (AComA) is formed by joining of the distal right and left first segments of the anterior cerebral artery (A1), one of the crucial anastomotic structure of the anterior cerebral circulation (1-3). As indicated in many previous studies AcomA anatomy shows variability. Mean length of AComA is between 2-3 mm with an average diameter of $1.6 \mathrm{~mm}$ was reported (1-3). The most common location of the intracranial aneurysms is the 
AComA with approximately $30-37 \%$ intracranial aneurysms seen in this region (4-6). Many neurosurgeons focused on these type aneurysms in the previous studies and also, one of the pioneer neurosurgeon, Yasargil classified the AComA into the 4 group according to the dome projections, the anterior projection, posterior projection, superior projection, inferior projection $(7,8)$. Classical and modified approaches for AComA aneurysms are classified as lateral and anterior groups. The lateral group: Pterional approach (PA), orbitozygomatic approach, orbitopterional approach. The anterior group: Anterior interhemispheric approach (AIHA), subfrontal approach $(9,10)$.

In this study, we aim to reveal the anatomical features of the AIHA and PA for AComA aneurysms surgery with detailed anatomic images and we explain the advantages of PA and AlHA according to Yasargil classification.
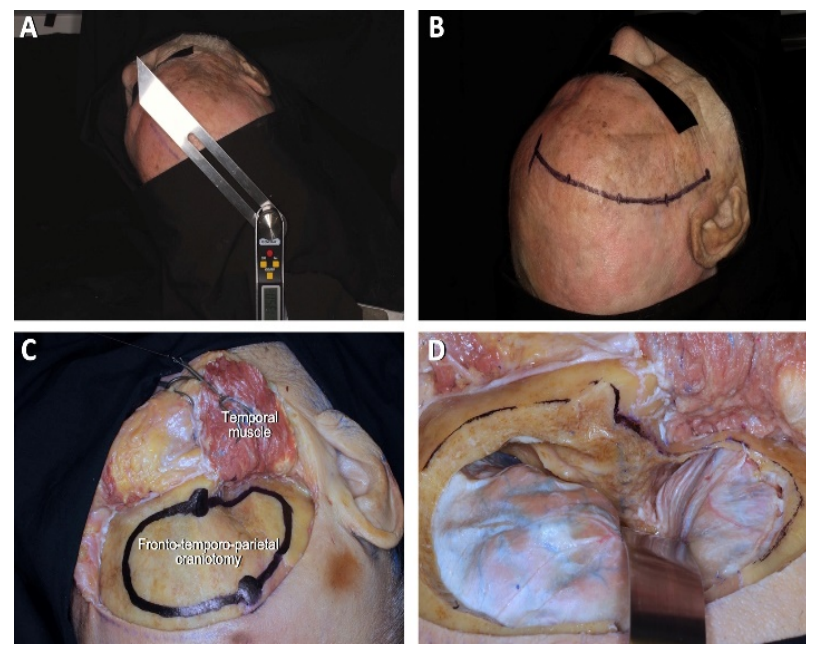

Figure 1. Used electronic protractor (7" Electronic Protractor Digital Goniometer, Preciva, Japan) to show the rotated head with 20 degrees extension and 45 degrees rotation in this picture (A). The curvilinear skin incision of the standard pterional approach (PA) may be shown (B). Showing the borders and size of the suitable craniotomy for standard PA (C). Drilling the great wing of the sphenoidal bone and retraction of the dura mater before opening the dura (D) Abbreviations: PA, pterional approach

\section{MATERIAL AND METHOD}

Four formalin-fixed and silicone injected human heads (8 sides) were used for AlHA and PA at the University of Minnesota Neuroanatomy Laboratory (Minneapolis, Minnesota, United States). Möller 201000 microscope (Wedel, Germany) was used for dissection and the vascular structures were examined
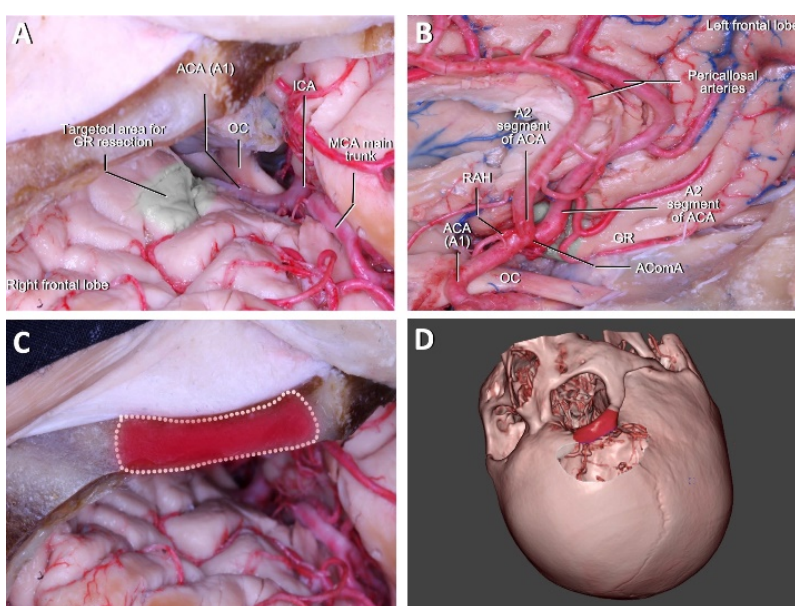

Figure 2: Exposure after performing the PA. Related area (green painted) for in resection during AComA aneurysm surgery via PA. GR resection and posterolateral orbitotomy, lateral exposure (A), medial exposure (B). Highlights of the anterolateral progression of surgical exposure. Red area represents the orbitotomy area ' $n$ cadaveric dissection $(C)$ and in $3 D$ computed tomography. Abbreviations: AComA, anterior communicating artery; GR, gyrus rectus; PA, pterional approach

using power zoom 1:6 magnification. All the photographs were obtained at a similar angle to the surgical microscope, at suitable head position as described in the following section, with Canon EOS Rebel T5 Digital SLR Digital Camera with EF $100 \mathrm{~mm}$ f/2.8L Macro IS USM Lens and a Canon MR-14EX II Macro Ring Lite Flash (Canon Inc., Ohta-ku, Tokyo, Japan) for all dissection stages. Our method includes AIHA and PA with GR resection and posterolateral orbitotomy. Procedural protocol of the PA includes dissection of Sylvian fissure (SF), A1, A2 (second part of anterior cerebral artery), internal carotid artery (ICA), proximal middle cerebral artery (MCA), optic chiasm, resection of the GR posterior and posterolateral orbitotomy. Dissection of distal branches of anterior cerebral artery (ACA) and bilateral $\mathrm{A} 1$ and superior surface of optic chiasm and around of lamina terminalis are included in AlHA.

\section{RESULTS}

\section{Pterional Approach}

45 degree head rotation is required, the head extension should be fixed at around 10-15 degree for anterior and inferior projections, up to 20 degree for superior and posterior projections of AComA aneurysms for PA $(4,11)$. We adjusted the heads with an electronic protractor (7" Electronic Protractor Digital Goniometer, Preciva, Japan) with 20 degrees extension and 45 degrees rotation (Figure 1A). The 


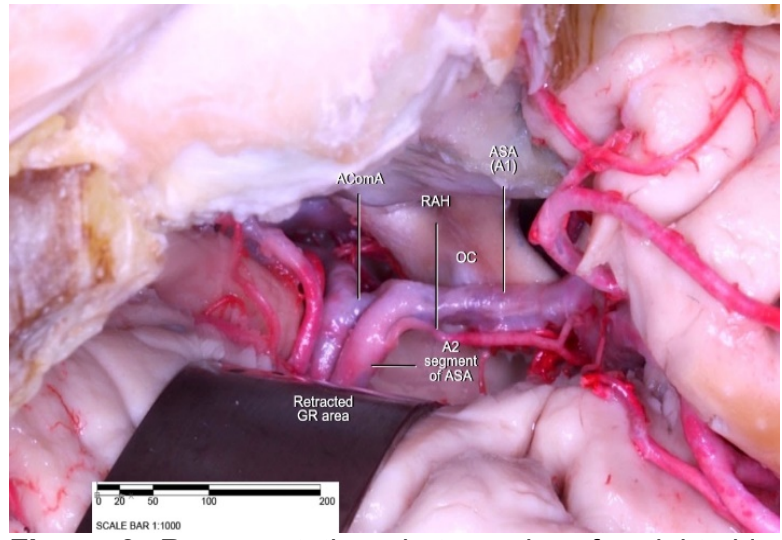

Figure 3. Representative photographs of a right-sided $P E$ with orbitotomy $(A)$, and before the procedure. Abbreviations: PA, pterional approach.
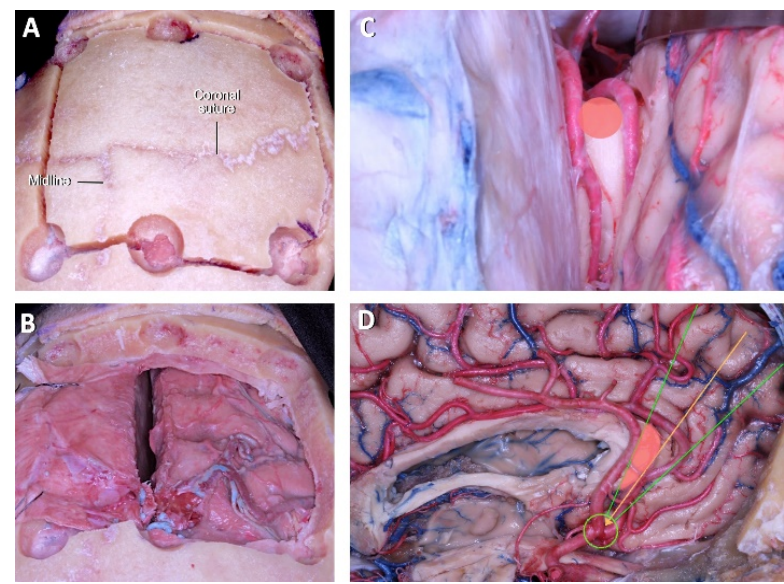

Figure 4: Superior view for craniotomy of AlHA (A). The craniotomy flap is extended inferiorly as close to the anterior cranial fossa floor as possible. Dura is opened with a semicircular flap based against the superior sagittal sinus and large and posteriorly located bridging frontal veins should be preserved (B). Superior (C) and medial (D) view in AlHA. Midline exposure enables the dura to be opened and provides directly accesses via the interhemispheric fissure. Abbreviations: AlHA, Anterior interhemispheric approach

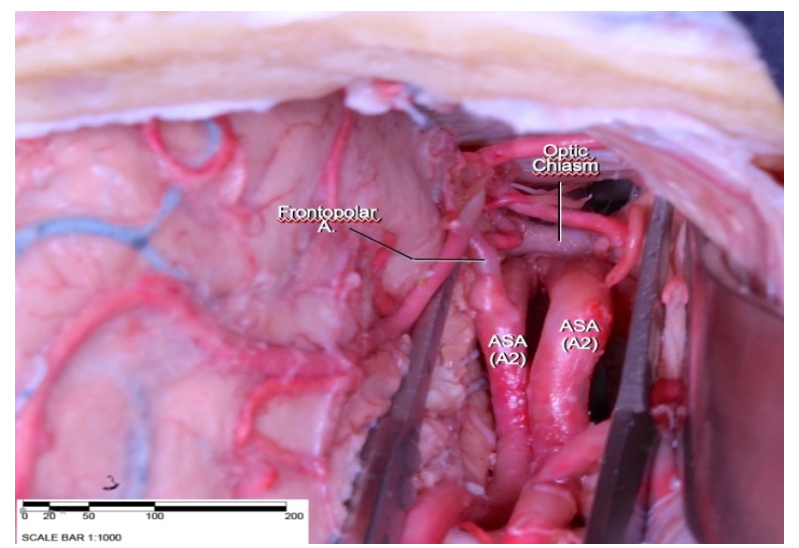

Figure 5: Pericallosal arteries, superior optic chiasm and AComA are exposed optimally following the dissection. Abbreviations: AComA, anterior communicating artery frontotemporal oblique skin incision behind the hairline was preferred (Figure 1B). The temporal muscle was split carefully. Next, standard $4 \times 7 \mathrm{~cm}$ sized frontotemporoparietal craniotomy was performed as has been described by Yasargil (Figure 1C) (8). The size of the craniotomy depends on surgical experience. The craniotomy can be extended as required to create an optimal surgical corridor for AComA aneurysm. The sphenoid ridge was drilled and the orbital roof was flattened (Figure 1D).

The next stage is intracranial, we need to use microsurgical techniques to minimize injury to brain tissue and vessels. After opening the dura, the surgery was done under the microscope. We did wide SF dissection from distal to proximal. This type of dissection provides better manipulation and wider surgical corridor with minimal retraction (12). After dissecting the SF and exposing carotid and optic cistern, the lamina terminalis was opened. The MCA, ACA arise from ICA and the A1 runs as the first part of post-AComA (A2), also the recurrent artery of Heubner (RAH) arises from junction of $A 1-A 2$. The ICA, proximal MCA, A1, A2, optic chiasm and the $\mathrm{RAH}$ were exposed $(13,14)$. The frontal lobe was retracted sufficiently for optimal viewing and to minimize the risk of aneurysm rupture. The gyrus rectus (GR) resection and posterolateral orbitotomy were performed following PA (Figure 2). The GR, a part of the base of frontal lobe usually covers the AComA. The ACOM area can be exposed by the resection of the GR (4). Subpial resection from posterior part of $G R$ is required for AComA aneurysms surgery $(4,15)$. We made a $1 \times 1 \mathrm{~cm}$ resection from posterior part of GR for ideal viewing. After this, posterolateral orbitotomy was performed and the orbital roof was removed up to the superior orbital fissure (Figure 3).

\section{Anterior Interhemispheric Approach}

The heads were fixed with a geometric protractor around 10-15 degrees extension and 0 degrees rotation in the supine position. We preferred frontal incision behind the hairline. Four burr holes were made and nearly $4 \times 7 \mathrm{~cm}$ bifrontal craniotomy was performed. Another approach that can be used is, a frontal craniotomy between just behind the coronal suture and the frontal sinus. The bone flap should be removed carefully avoiding any damage to the vascular structures. The craniotomy on the coronal suture was performed and the dura was opened on 

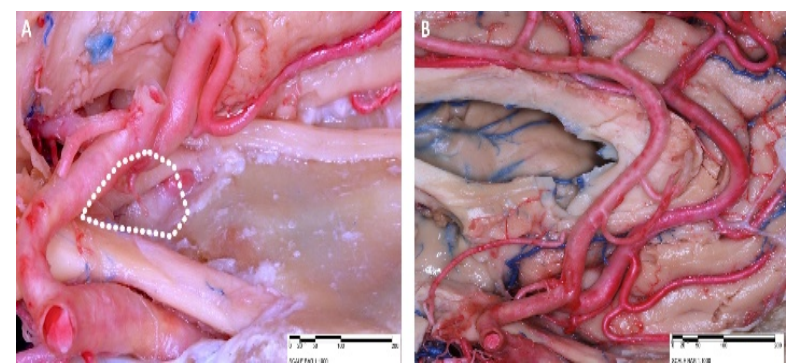

Figure 6. Medial view. Supra chiasmatic dissection for exposing the area below the AComA. A1 and A2 junction and the pericallosal arteries were identified and dissected to reveal the AComA aneurysm. Abbreviations: AComA, anterior communicating artery.
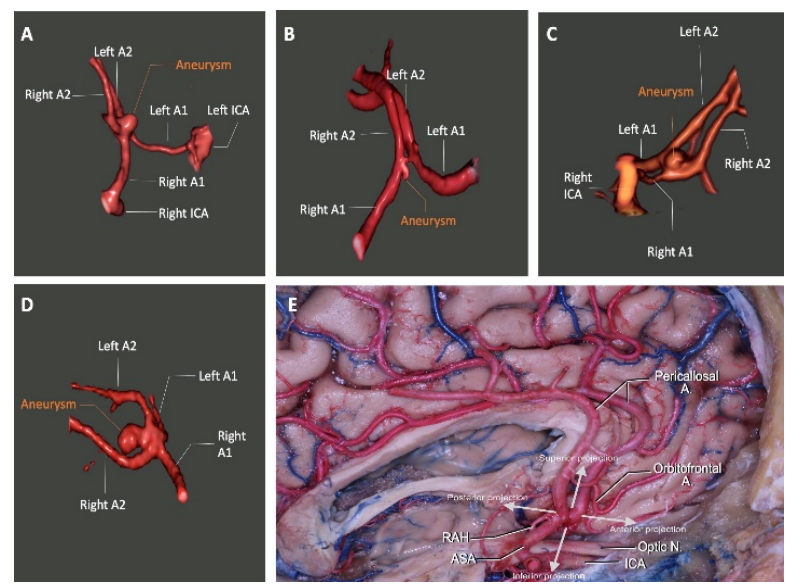

Figure 7. Anterior $(A)$, inferior $(B)$, posterior $(C)$, superior (D) projecting aneurysms in 3D computerized tomography according Yasargil classification and their directions in medial view $(E)$.

one side and overthrown to the midline (Figure 4A, B). The interhemispheric fissure was dissected parallel to the frontal surface (Figure 4C, D). After this the arachnoid mater was open and the tightness of the falx was reduced with sharp dissection (Figure 5) Large and posteriorly located bridging frontal veins should be preserved. Creating a suitable surgical corridor for optimal viewing of AComA is crucial. After this stage, $A 1$ and $A 2$ junction and the pericallosal arteries were identified and dissected to reveal the AComA aneurysm. The AIHA allows better visualization of the anterior and inferior surface of AComA, A1-A2 junction and the optic nerves related with this area (Figure 6). Both AIHA and PA have some advantages and disadvantages and potential surgical difficulties which vary according to the location and direction of the AComA aneurysms.

\section{Aneurysm Characteristics}

The AComA aneurysms was classified by Yasargil (8) according to the dome projections but we can further separate the aneurysms into the 2 groups according to the preferable approach in literature . Group 1 includes superiorly projected and high positioned aneurysms and group 2 includes inferior, anterior and posterior projecting aneurysms (Figure 7).

\section{DISCUSSION}

Microsurgery to the AComA and surrounding structures is very complicated and is a challenging for the neurosurgeons $(4,16)$. The most important structures are AComA, both side $A 1$ and $A 2, R A H$, hypothalamic and chiasmal perforates (4). The working area in the interhemispheric fissure and callosal cistern is so limited. Also, cingulate gyrus, pial layer adhesions and venous vessels provide harder sharp dissection during the surgery. (17).

Our aim is to compare the advantages, disadvantages and effectivity for PA and AIHA to reveal significant anatomic differences at surgical head positions for preoperative planning of AComA aneurysms surgery based on 4 projections (Table 1 , 2). The most suitable approach should provide the needed surgical corridor and optimal manipulation without brain damage, with minimal retraction for final clipping of AComA aneurysms (18). When the approach is decided, direction, sizes and locations of the AComA aneurysms should be considered for surgical strategy $(9,10)$. The non-dominant (right) side can be chosen to decrease the neurologic deficit because the surgeons are usually more experienced on this side and majority are right handed (6).

We explain the most suitable aneurysms for AIHA and the combination of the PA with GR resection and posterolateral orbitotomy based on the aneurysm dome projection. Based on Yasargil classification (8), the AIHA is preferred for group 1 which closely related with the interhemispheric fissure. PA is preferred for group 2, but this determination can change according to the surgeon's experience and orientation $(7-9,19)$. The PA is the easier and conventional approach, therefore PA is preferred more than AIHA (20). In addition, some studies have stated that the AIHA is more suitable for posterior projecting aneurysms (1). Wider retraction is required for PA and can cause brain damage. Many studies reported the techniques of the GR resection and orbitotomy for creating a suitable surgical angle and facilitating the surgery especially in younger patients with brain swelling caused by hemorrhage $(4,18,21,22)$. The AIHA is 
Table 1. Data about the pterional approach with gyrus rectus resection and orbytotomy

\begin{tabular}{|c|c|c|c|c|c|}
\hline References & $\begin{array}{l}\mathrm{N}=\text { Associated } \\
\text { cases with } \\
\text { target } \\
\text { aneurysm }\end{array}$ & $\begin{array}{l}\text { Positional } \\
\text { characteristic of } \\
\text { target lesion } \\
\text { related with } \\
\text { AComA }\end{array}$ & $\begin{array}{l}\mathrm{N}=\text { Resection } \\
\text { of GR }\end{array}$ & Orbitotomy & Comment \\
\hline $\begin{array}{l}\text { Kashimura } \\
\text { et al. (20) }\end{array}$ & 24 cases & $\begin{array}{l}\text {-Posterior } \\
\text { projection } \\
\text {-Superior } \\
\text { projection }\end{array}$ & $\begin{array}{l}(+)=4 \\
(-)=17\end{array}$ & No & $\begin{array}{l}\text { ! The dissection technique beyond the midline } \\
\text { of the optic chiasm is helpful for dissecting the } \\
\text { interhemispheric fissure and the aneurysms } \\
\text { sufficiently. } \\
\text { !! When the aneurysms projects toward the left } \\
\text { or right side, the resection gyrus rectus is } \\
\text { required. }\end{array}$ \\
\hline $\begin{array}{l}\text { Yun et al. } \\
\text { (9) }\end{array}$ & $\begin{array}{l}231 \text { cases } \\
\text { (number of } \\
\text { cases with PA } \\
\text { are } \\
\text { unspecified) }\end{array}$ & $\begin{array}{l}\text {-High positioned } \\
\text {-Large sized and } \\
\text { complex } \\
\text {-Inferior } \\
\text { projection } \\
\text {-Anterior } \\
\text { projection } \\
\text {-Posterior } \\
\text { projection }\end{array}$ & $\begin{array}{l}(+)=96 \text { (with } \\
\text { sylvian } \\
\text { fissure } \\
\text { dissection) } \\
(-)=135 \\
\text { (without } \\
\text { sylvian } \\
\text { fissure } \\
\text { dissection) }\end{array}$ & No & $\begin{array}{l}\text { ! The resection of the gyrus rectus without } \\
\text { sylvian fissure provides suitable surgical } \\
\text { corridor for AComA aneurysms and view of } \\
\text { ipsilateral A1 and A2. } \\
\text { !! The main aim is improving the view of } \\
\text { AComA aneurysms and decreasing the risk of } \\
\text { frontal and temporal lobe damage. }\end{array}$ \\
\hline $\begin{array}{l}\text { Hyun et al. } \\
\text { (31) }\end{array}$ & 19 cases & $\begin{array}{l}\text {-Superior } \\
\text { projection }\end{array}$ & $\begin{array}{l}(+)=9 \\
(-)=10\end{array}$ & No & $\begin{array}{l}\text { ! GR should be resected in cases where the } \\
\text { aneurysm is close to A2 segment to enlarge the } \\
\text { corridor. } \\
\text { !! AlHA can be considered as another option, } \\
\text { as superior or high positioned aneurysms have } \\
\text { a high risk of complications. }\end{array}$ \\
\hline $\begin{array}{l}\text { Horikoshi } \\
\text { et al. (15) }\end{array}$ & 194 cases & $\begin{array}{l}\text {-Superior } \\
\text { projection } \\
\text {-High positioned }\end{array}$ & $\begin{array}{l}(+)=52 \\
(-)=142\end{array}$ & No & $\begin{array}{l}\text { ! GR resection does not change the recovery } \\
\text { results of the patients after discharging. } \\
\text { !! GR should be resected in cases where the } \\
\text { aneurysm projects superiorly. } \\
\text { !!! GR resection should be done more } \\
\text { frequently in cases where the brain is swollen. } \\
\text { !!!! Resection with minimal frontal retraction can } \\
\text { decrease the risk of premature rupture. }\end{array}$ \\
\hline $\begin{array}{l}\text { Kim et al. } \\
(18)\end{array}$ & 113 cases & $\begin{array}{l}\text {-Superior } \\
\text { projection } \\
\text {-Inferior } \\
\text { projection } \\
\text {-Posterior } \\
\text { projection } \\
\text {-Anterior } \\
\text { projection }\end{array}$ & $\begin{array}{l}(+)=113 \\
(-)=0 \\
\text { (It was done } \\
\text { routinely) }\end{array}$ & No & $\begin{array}{l}\text { ! Suitable interhemispheric surgical corridor } \\
\text { provides better view of hypothalamic branch } \\
\text { and allows to preserve these branches and } \\
\text { cognitive function, but it should only be used for } \\
\text { unruptured aneurysm smaller than } 10 \mathrm{~mm} \text { in } \\
\text { size. } \\
\text { !! The resection of GR may help visualization of } \\
\text { the A2 segments and the A1 dominancy. }\end{array}$ \\
\hline $\begin{array}{l}\text { Sekhar et } \\
\text { al. (4) }\end{array}$ & $\begin{array}{l}39^{*} \text { cases } \\
\text { (underwent } \\
\text { surgery / } 194 \\
\text { cases) }\end{array}$ & $\begin{array}{l}\text {-Posterosuperior } \\
\text { projection } \\
\text {-Anterosuperior } \\
\text { projection } \\
\text {-Anterior } \\
\text { projection } \\
\text {-Inferior } \\
\text { projection }\end{array}$ & $\begin{array}{l}\text { Yes, (number } \\
\text { of resection, } \\
\text { unspecified) }\end{array}$ & $\begin{array}{l}\text { Yes, } \\
\text { (posterolate } \\
\text { ral } \\
\text { orbitotomy } \\
\text { up to } \\
\text { superior } \\
\text { orbital } \\
\text { fissure) }\end{array}$ & $\begin{array}{l}\text { ! Partial resection of posterior GR is necessary } \\
\text { for reaching the contralateral A1. } \\
\text { !! Anatomical details are crucial for surgical } \\
\text { strategy. } \\
\text { !!! The brain condition affects the surgical } \\
\text { technique. When the brain is swollen, the } \\
\text { orbitotomy can be performed, but if the brain is } \\
\text { slack, the orbitotomy might not be necessary. }\end{array}$ \\
\hline $\begin{array}{l}\text { Banerjee et } \\
\text { al. (C) (32) }\end{array}$ & $\begin{array}{l}5 \text { cadaveric } \\
\text { heads } \\
10 \text { sides }\end{array}$ & $\begin{array}{l}\text {-The midpoint of } \\
\text { the AComA }\end{array}$ & $\begin{array}{l}\text { Yes, (number } \\
\text { of resection, } \\
\text { unspecified) }\end{array}$ & $\begin{array}{l}\text { Yes, } \\
\text { (posterolate } \\
\text { ral } \\
\text { orbitotomy } \\
\text { up to } \\
\text { superior } \\
\text { orbital } \\
\text { fissure) }\end{array}$ & $\begin{array}{l}\text { ! The crucial factor is to reach the AComA } \\
\text { complex without GR resection. } \\
\text { !! The extended pterional approach with } \\
\text { orbitotomy is an important technique when the } \\
\text { aneurysm projects superiorly. } \\
\text { !!! The orbitopterional approach without GR } \\
\text { resection is more effective than the pterional } \\
\text { approach with GR resection. }\end{array}$ \\
\hline
\end{tabular}

$(+)=$ Gyrus rectus has been resected, $(-)=$ Gyrus rectus has not been resected .

* Number of patients who operated AlHA or PA. (C) Cadaveric study 
Table 2. Data about characteristics of the AComA aneurysms

\begin{tabular}{|c|c|c|c|}
\hline References & $\begin{array}{l}\mathrm{N}= \\
\text { Associated } \\
\text { cases }\end{array}$ & $\begin{array}{l}\text { Positional } \\
\text { characteristic of target } \\
\text { lesion }\end{array}$ & Comment \\
\hline $\begin{array}{l}\text { Yun et al. } \\
(9)\end{array}$ & $\begin{array}{l}231 \text { patients } \\
\text { (number of } \\
\text { cases with } \\
\text { AlHA are } \\
\text { unspecified) }\end{array}$ & $\begin{array}{l}\text {-High positioned } \\
\text {-Large sized and complex } \\
\text {-Inferior projection }\end{array}$ & $\begin{array}{l}\text { ! Detailed anatomy, size, projection of the AComA aneurysm } \\
\text { determine the suitable clipping technique and approach [8]. } \\
\text { !! The AlHA is better when the aneurysm projects superiorly or } \\
\text { high positioned. AlHA can be used for superior and high } \\
\text { positioned aneurysms because PA has a high risk of } \\
\text { complications. }\end{array}$ \\
\hline $\begin{array}{l}\text { Hernesniemi } \\
\text { et al. (28) }\end{array}$ & 898 patients & $\begin{array}{l}\text {-Downward projecting } \\
\text {-Forward projecting } \\
\text {-Upward projecting } \\
\text {-Backward projecting }\end{array}$ & $\begin{array}{l}\text { ! AlHA, which needs minimal retraction and no resection of GR is } \\
\text { suggested when the base of AComA aneurysm is more than } 13 \\
\text { mm and above the skull base, is either forward projecting or } \\
\text { backward projecting and high positioned. } \\
\text { !! The right side is more appropriate than left side. It is needed to } \\
\text { create optimal angle of microscope and surgical orientation. }\end{array}$ \\
\hline $\begin{array}{l}\text { Sekhar et al. } \\
(4)\end{array}$ & $\begin{array}{l}39^{*} \text { patients } \\
\text { (underwent } \\
\text { surgery / } \\
194 \\
\text { patients) }\end{array}$ & $\begin{array}{l}\text {-Posterosuperior } \\
\text { projection } \\
\text {-Anterosuperior } \\
\text { projection } \\
\text {-Anterior projection } \\
\text {-Inferior projection }\end{array}$ & $\begin{array}{l}\text { ! The AlHA is preferred when experienced surgeons need better } \\
\text { view of A2 and for clipping of large or giant AComA aneurysms. } \\
\text { !! If the standard AlHA is used, on reaching the aneurysm, sharp } \\
\text { dissection around the target aneurysm should be avoided. }\end{array}$ \\
\hline $\begin{array}{l}\text { Suzuki et al. } \\
(24)\end{array}$ & 603 patients & $\begin{array}{l}\text {-Superior projection } \\
\text { - Lateral projection }\end{array}$ & $\begin{array}{l}\text { ! The interhemispheric fissure allows for dissection around the } \\
\text { AComA complex without damage to the medial surface [23]. } \\
\text { !! Once we reach the aneurysm dome, aggressive dissection } \\
\text { should be avoided. } \\
\text { !!! Opening the frontal sinus increases the infection rate and } \\
\text { olfactory nerve damage which are crucial post operative } \\
\text { outcomes. }\end{array}$ \\
\hline $\begin{array}{l}\text { Srour et al. } \\
\text { ( ) (33) }\end{array}$ & 10 cadavers & Unspecified & $\begin{array}{l}\text { ! AlHA provides optimal orientation, manipulation and a better } \\
\text { view with minimal retraction. It does not require GR resection and } \\
\text { has a low risk of post-operative spasm [31]. } \\
\text { !! The AlHA decreases the risk of accidentally clipping the } \\
\text { recurrent artery of Heubner and perforating branches [31]. } \\
\text { !!! AlHA has a potential infection risk because of the opening of } \\
\text { frontal sinus. }\end{array}$ \\
\hline
\end{tabular}

preferred more than the PA as it needs minimal retraction, does not need $G R$ resection and has a lower chance of causing vascular injuries $(1,18)$. If AComA is superiorly projecting, our main aim should be to reveal the aneurysms completely with wider retraction, but with $\mathrm{PA}$ this dissection is very difficult and can cause brain damage (20). In AIHA, depending on where the retractor blade is placed, the commonest complication is olfactory nerve damage, followed by an infection related to opening the frontal sinus $(1,23,24)$. In literature, some studies have recommended to perform the craniotomy a little behind the coronal suture without opening the frontal sinus and to resect some part of the anterior corpus callosum for adequate exposure $(25,26)$. The surgical corridor for AIHA is usually between A2 and the AComA. The aneurysms usually originate from the dominant $A 1$, consequently $A 1$ and both $A 2$ should be exposed sufficiently for temporary clipping $(5,27)$. The main problem for AComA aneurysms directed superiorly is to reach distal control before proximal during this dissection process (25). In addition, the arachnoid mater can keep the A2 segment in the interhemispheric fissure and the frontal lobe can be damaged during the opening dissection (21).

The PA is controversial for group 1 but many studies recommend combining PA with GR resection and/or a posterolateral orbitotomy for group 2. In our study, we determined that this process provides better manipulation and a wider surgical corridor. If the PA is performed, GR resection is absolutely necessary and when the brain is swollen, the posterolateral orbitotomy if needed $(9,18,28,29)$. Resection of the GR has the crucial benefit of providing better proximal sharp exposure for A1, A2 and olfactory nerve with the main aim being minimal retraction $(24,30)$ According to some studies, when the direction of the aneurysm is posterior, anterior or inferior and the brain is slack, GR resection is enough for optimal clipping without SF dissection $(6,9)$. In addition, approximately $1 \times 1 \mathrm{~cm}$ posterior part of GR resection is required (15). If the PA is performed, the head should be fixed at 20 degrees extension for group 1 , around 10-15 degree for group 2. More than 20 
degrees head extension can close the surgical corridor and the area around AComA. Consequently, many studies have reported that orbitotomy is required for suitably exposing this region $(6,11)$.

When the direction of AComA aneurysms is anterior or inferior, they can be related with upper part of the optic chiasm. The aneurysm may rupture depending on arachnoid adhesions which is in close relationship with these structures during the dissection (30). Consequently, surgical approach should be performed from the same side as the dominant $A 1$ for inferior and posterior type aneurysms to provide maximal control for temporary clipping, if needed (20). For superior aneurysms, with PA, GR resection is necessary for exposing the posterior area of $A 2$ as the hypothalamic and subcallosal arteries can be damaged during this dissection. The aneurysmal fundus may be dissected first to decrease the risk of injury. If the surgeon is experienced, AIHA may be performed (4). Also, one of the most common related arteries to AComA is RAH which approximately $90 \%$ of the times arises from the A1-A2 junction. RAH may be accidentally clipped during the final clipping, for this reason the origin of RAH should be dissected and revealed carefully $(1,31-33)$.

\section{CONCLUSIONS}

We believe the PA combined with $G R$ resection and posterolateral orbitotomy is more suitable for anterior, posterior and inferior projections aneurysms. In addition, AlHA is accepted a safer approach for superior and high positioned AComA aneurysms.

Acknowlegement: The anatomical microsurgical dissection has been performed under-mentorship of Associated Prof. Grande at Microsurgical Neuroanatomy Laboratory, University of Minnesota, Minneapolis, Minnesota, United States, Department of Neurosurgery. I would like to thank Associated Prof. Grande, fellows and director of the laboratory for their support during the work.

Peer-review: Externally peer-reviewed.

\section{REFERENCES}

1. Hernesniemi J, Dashti R, Lehecka M, Niemela M, Rinne J, Lehto $H$, et al. Microneurosurgical management of anterior communicating artery aneurysms. Surg Neurol. 2008;70(1):8-28.

2. Perlmutter $D$, Rhoton $A L$, Jr. Microsurgical anatomy of anterior cerebral anterior communicating recurrent artery complex. Surg Forum. 1976;27(62):464-5.
3. Yasargil MG. Microneurosurgery. Stuttgart: Georg Thieme Verlag; 1984. 5-168 p.

4. Sekhar LN, Natarajan SK, Britz GW, Ghodke B. Microsurgical management of anterior communicating artery aneurysms. Neurosurgery. 2007;61(5 Suppl 2):273-90.

5. Kim SY, Jeon HJ, Ihm EH, Park KY, Lee JW, Huh SK. Microsurgical efficacy and safety of a righthemispheric approach for unruptured anterior communicating artery aneurysms. Clin Neurol Neurosurg. 2015;137:62-6.

6. Andaluz N, Van Loveren HR, Keller JT, Zuccarello M. Anatomic and clinical study of the orbitopterional approach to anterior communicating artery aneurysms. Neurosurgery. 2003;52(5):1140-8.

7. Yasargil MG. Microneurosurgery. Stuttgart: Georg Thieme Verlag; 1984. 169-224 p.

8. Yasargil MG. Microneurosurgery. Stutgart: Georg Thieme Verlag; 1984. 217-20 p.

9. Yun JK, Kang SD, Kim JM. Clipping of the Anterior Communicating Artery Aneurysm without Sylvian Fissure Dissection. J Korean Neurosurg Soc. 2007;42(5):388-91.

10.El-Noamany H, Nakagawa F, Hongo K, Kakizawa Y, Kobayashi S. Low anterior interhemispheric approach--a narrow corridor to aneurysms of the anterior communicating artery. Acta Neurochir (Wien). 2001;143(9):885-91.

11. Chaddad-Neto F, Doria-Netto HL, Campos-Filho JM, Ribas ES, Ribas GC, Oliveira E. Head positioning for anterior circulation aneurysms microsurgery. Arq Neuropsiquiatr. 2014;72(11):832-40.

12. Heros RC, Fritsch MJ. Surgical management of middle cerebral artery aneurysms. Neurosurgery. 2001;48(4):780-5.

13.Dunker RO, Harris AB. Surgical anatomy of the proximal anterior cerebral artery. J Neurosurg. 1976;44(3):359-67.

14.Kawashima $M$, Rhoton $A L$, Jr., Tanriover $N$, UIm AJ, Yasuda A, Fujii K. Microsurgical anatomy of cerebral revascularization. Part I: anterior circulation. J Neurosurg. 2005;102(1):116-31.

15. Horikoshi T, Nukui $H$, Mitsuka S, Kaneko M. Partial resection of the gyrus rectus in pterional approach to anterior communicating artery aneurysms. Neurol Med Chir (Tokyo). 1992;32(3):136-9.

16.Liu P, Pan L, An X, Ma L, Yang M. Effect of clipping anterior communicating artery aneurysms 
via pterional approach contralateral to supply of dominant blood: report of 15 patients. Int $\mathrm{J}$ Clin Exp Med. 2015;8(2):1912-7.

17.Kawashima M, Matsushima T, Sasaki T. Surgical strategy for distal anterior cerebral artery aneurysms: microsurgical anatomy. J Neurosurg. 2003;99(3):517-25.

18.Kim H, Kim TS, Joo SP, Moon HS. Pterionalsubolfactory Approach for Treatment of High Positioned Anterior Communicating Artery Aneurysms. J Cerebrovasc Endovasc Neurosurg. 2013;15(3):177-83.

19.Suzuki $M$, Fujisawa $H$, Ishihara $H$, Yoneda $H$, Kato $\mathrm{S}$, Ogawa A. Side selection of pterional approach for anterior communicating artery aneurysms-surgical anatomy and strategy. Acta Neurochir (Wien). 2008;150(1):31-9.

20.Kashimura $\mathrm{H}$, Kubo $\mathrm{Y}$, Ogasawara K, Kakino S, Yoshida K, Ogawa A. Easy dissection of the interhemispheric fissure for treatment of the anterior communicating artery aneurysm by the pterional approach. World Neurosurg. 2010;73(6):688-90.

21.de Sousa AA. Tips to the dissection of the interhemispheric fissure for the treatment of the anterior communicating artery aneurysm through the pterional approach. World Neurosurg. 2010;73(6):624.

22.Effendi ST, Momin EN, Basma J, Michael LM, Duckworth EAM. The Ultimate Skull Base Maneuver Does Not Involve Removing Bone: Quantifying the Benefits of the Interfascial Dissection. J Neurol Surg B Skull Base. 2020;81(1):62-7.

23. Matano F, Murai $\mathrm{Y}$, Mizunari T, Tateyama K, Kobayashi S, Adachi $\mathrm{K}$, et al. Olfactory preservation during anterior interhemispheric approach for anterior skull base lesions: technical note. Neurosurg Rev. 2016;39(1):63-9.

24.Suzuki J, Mizoi K, Yoshimoto T. Bifrontal interhemispheric approach to aneurysms of the anterior communicating artery. J Neurosurg. 1986;64(2):183-90.

25.Traynelis VC, Dunker RO. Interhemispheric approach with callosal resection for distal anterior cerebral artery aneurysms. Technical note. J Neurosurg. 1992;77(3):481-3.

26.Mielke D, Mayfrank L, Psychogios MN, Rohde V. The anterior interhemispheric approach: a safe and effective approach to anterior skull base lesions. Acta Neurochir (Wien). 2014;156(4):68996.

27.Fujiwara $\mathrm{H}$, Yasui $\mathrm{N}$, Nathal-Vera E, Suzuki A. Anosmia after anterior communicating artery aneurysm surgery: comparison between the anterior interhemispheric and basal interhemispheric approaches. Neurosurgery. 1996;38(2):325-8.

28. Hernesniemi J, Ishii K, Niemela M, Smrcka M, Kivipelto L, Fujiki M, et al. Lateral supraorbital approach as an alternative to the classical pterional approach. Acta Neurochir Suppl. 2005;94:17-21.

29.Kempe LG, VanderArk GD. Anterior communicating artery aneurysms. Gyrus rectus approach. Neurochirurgia (Stuttg). 1971;14(2):6370.

30. Hendricks BK, Spetzler RF. Orbitozygomatic Approach Clipping of an Anterior Communicating Artery Aneurysm: 2-Dimensional Operative Video. Oper Neurosurg (Hagerstown). 2020;18(5):E160.

31. Hyun SJ, Hong SC, Kim JS. Side selection of the pterional approach for superiorly projecting anterior communicating artery aneurysms. J Clin Neurosci. 2010;17(5):592-6.

32.Brown B, Banerjee AD, Wadhwa R, Nourbakhsh A, Caldito G, Nanda A, et al. When is posterolateral orbitotomy useful in a pterional craniotomy? A morphometric study. Skull Base. 2011;21(3):147-52.

33.Srour A, el Tantawi AM, Khouja N, Zouaoui A, Lassau JP, Philippon J, et al. Neurosurgical anatomy of the anterior interhemispheric approach for aneurysms of the anterior communicating artery (26.6.92). Surg Radiol Anat. 1994;16(1):117-9. 